\title{
Kumada-Corriu Reactions of Alkyl Halides with Alkynyl Nucleophiles
}

\author{
Lian-Ming Yang, ${ }^{\dagger}$ Li-Fu Huang, ${ }^{\dagger, \ddagger}$ and Tien-Yau Luh ${ }^{\star, \dagger, \neq, \S}$ \\ Department of Chemistry and Institute of Polymer Science and Engineering, \\ National Taiwan University, Taipei, Taiwan 106, and Institute of Chemistry, \\ Academia Sinica, Nangang, Taipei, Taiwan 115
}

tyluh@chem.sinica.edu.tw

Received February 23, 2004

\section{ABSTRACT}

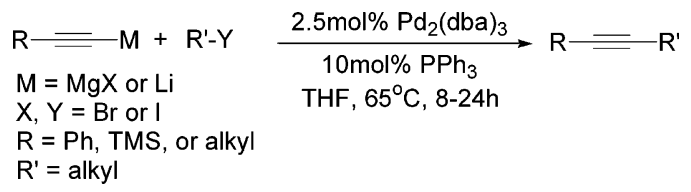

$\mathrm{Pd}_{2}(\mathrm{dba})_{3}-\mathrm{Ph}_{3} \mathrm{P}$-catalyzed Kumada-Corriu coupling reactions of unactivated alkyl bromides or iodides with an alkynyl nucleophile furnish $\mathrm{C}_{\mathrm{sp}}-\mathrm{C}_{\mathrm{sp}} 3$ bond formation. Alkynyl nucleophiles can be alkynyllithiums or the corresponding Grignard reagents. The superior performance of $\mathrm{Ph}_{3} \mathrm{P}$ ligand over the trialkylphosphine ligands indicates that this cross-coupling reaction may be a reductive-elimination-controlled process.

Transition metal-catalyzed cross couplings have provided a very powerful arsenal for carbon-carbon bond formation. ${ }^{1}$ The mechanism for these important reactions, in general, involves (i) oxidative addition of an organic electrophile to a low-valent metal center and (ii) transmetalation to give a diorganometallic derivative, followed by (iii) a reductive elimination process to yield the coupling product with concomitant regeneration of the low-valent active metallic species for further catalytic cycling. ${ }^{1,2}$ The nature of the ligand(s) apparently plays a pivotal role on the activity of the catalyst. ${ }^{3-9}$ Trialkylphosphine ligands have recently been demonstrated to be particularly useful to facilitate coupling reactions of aliphatic electrophiles. ${ }^{4}$ Presumably, the oxidative addition across the $\mathrm{C}-\mathrm{X}$ bond may become more facile when an electron-rich metal catalyst is used. However, the

\footnotetext{
$\dagger$ Academia Sinica.

$\doteqdot$ Department of Chemistry, National Taiwan University.

$\S$ Institute of Polymer Science and Engineering, National Taiwan University.

(1) (a) Metal-Catalyzed Cross-Coupling Reactions; Diederich, F., Stang, P. J., Eds.; Wiley-VCH: New York, 1998. (b) Cross-Coupling Reactions: A Practical Guide; Miyaura, N., Ed.; Topics in Current Chemistry Series 219; Springer-Verlag: New York, 2002.

(2) Collman, P.; Hegedus, S.; Norton, R.; Finke, G. Principles and Applications of Organotransition Metal Chemistry; University Science Books: Mill Valley, CA, 1987; Chapters 4-6.

(3) For reviews see: (a) Luh, T.-Y.; Leung, M.-K.; Wong, K.-T. Chem. Rev. 2000, 100, 3187-3204. (b) Cárdenas, D. J. Angew. Chem., Int. Ed.
} 2003, 42, 384-387. electron demand for reductive elimination would be opposite to that for oxidative addition. In other words, electrondonating ligands may slow the catalytic process of crosscoupling reactions because the reductive elimination step may be decelerated. When the intermediate with the metal center in a higher oxidation state contains ligands that are vulnerable to oxidation, oxidative coupling of such ligands may lead to

(4) (a) Netherton, M. R.; Dai, C.; Neuschütz, K.; Fu, G. C. J. Am. Chem. Soc. 2001, 123, 10099-10100. (b) Kirchhoff, J. H.; Netherton, M. R.; Hills I. D.; Fu, G. C. J. Am. Chem. Soc. 2002, 124, 13662-13663. (c) Kirchhoff, J. H.; Dai, C.; Fu, G. C. Angew. Chem., Int. Ed. 2002, 41, 1945-1947. (d) Netherton, M. R.; Fu, G. C. Angew. Chem., Int. Ed. 2002, 41, 3910-3912. (e) Frisch, A. C.; Shaikh, N.; Zapf, A.; Beller, M. Angew. Chem., Int. Ed. 2002, 41, 4056-4059. (f) Menzel, K.; Fu, G. C. J. Am. Chem. Soc. 2003, 125, 3718-3719. (g) Lee, J. Y.; Fu, G. C. J. Am. Chem. Soc. 2003, 125, 5616-5617. (h) Huang, L.-F.; Huang, C.-H.; Stulgies, B.; de Meijere, A.; Luh, T.-Y. Org. Lett. 2003, 5, 4489-4491.

(5) (a) Zhou, J.; Fu, G. C. J. Am. Chem. Soc. 2004, 126, 1340-1341. (b) Zhou, J.; Fu, G. C. J. Am. Chem. Soc. 2003, 125, 12527-12530. (c) Zhou, J.; Fu, G. C. J. Am. Chem. Soc. 2003, 125, 14726-14727.

(6) (a) Devasagayaraj, A.; Stüdemann, T.; Knochel, P. Angew. Chem., Int. Ed. Engl. 1995, 34, 2723-2725. (b) Giovannini, R.; Stüdemann, T.; Dussin, G.; Knochel, P. Angew. Chem., Int. Ed. 1998, 37, 2387-2390. (c) Giovannini, R.; Stüdemann, T.; Devasagayaraj, A.; Dussin, G.; Knochel, P. J. Org. Chem. 1999, 64, 3544-3553. (d) Piber, M.; Jensen, A. E.; Knochel, P. Org. Lett. 1999, 1, 1323-1326. (e) Jensen, A. E.; Knochel, P. J. Org. Chem. 2002, 67, 79-85.

(7) (a) Terao, J.; Wantanabe, H.; Ikumi, A.; Kuniyasu, H.; Kambe, N. J. Am. Chem. Soc. 2002, 124, 4222-4223. (b) Terao, J.; Ikumi, A.; Kuniyasu, H.; Kambe, N. J. Am. Chem. Soc. 2003, 125, 5646-5647.

(8) Eckhardt, M.; Fu, G. C. J. Am. Chem. Soc. 2003, 125, 13642-13643.

(9) Lei, A.; Zhang, X. Org. Lett. 2002, 4, 2285-2288. 
the dimerization product(s). Indeed, palladium catalysts are known to mediate dimerization of terminal alkynes. ${ }^{10,11}$ Although the palladium-catalyzed coupling reactions of alkynyl Grignard reagents with $\mathrm{C}_{\mathrm{sp}} 2$ electrophiles are well documented, ${ }^{12,13}$ the corresponding Kumada-Corriu reaction with alkyl substrates is not known. Modified Sonogashira reaction using imidazolinylidene ligands appears to be the only known example of cross-coupling reaction of an aliphatic halide with an alkyne. ${ }^{8}$ We envisaged that a balance of the reactivity of oxidative addition and reductive elimination steps would be necessary to promote the cross-coupling reaction of alkyl halides and alkynyl Grignard reagents, and we now describe the first such palladium-catalyzed such coupling reaction.

In the beginning of this research, a mixture of phenylethynyl Grignard reagent 1 and 1 equiv of 1-bromooctane in the presence of a palladium catalyst and a phosphine ligand in THF was refluxed for $8 \mathrm{~h}$ (eq 1). A range of different catalysts and ligands were screened, and the product distributions are summarized in Table 1.

As can be seen in Table 1, palladium acetate in the presence of a phosphine ligand apparently was not an effective catalyst for this coupling reaction (entries 1-3). Instead, zero-valent palladium catalyst appears to be essential for this purpose. To our surprise, trialkylphosphine ligands were not as efficient as triphenylphosphine ligand in this coupling reaction. Indeed, the use of triphenylphosphine ligand has been known in the Suzuki coupling of alkyl halides. ${ }^{14}$ Although electron-donating trialkylphosphine ligands may accelerate the oxidative addition of low-valent palladium across aliphatic carbon-halogen bonds, our results, together with the literature data, ${ }^{9,12}$ suggested that such a step can occur even in the presence of less reactive triarylphosphine ligands.

It is known that $\mathrm{Cl}_{2} \mathrm{Pd}\left(\mathrm{PPh}_{3}\right)_{2}$ reacts with 2 equiv of alkynyllithium to form dimeric diyne and with excess alkynyllithium to afford $\mathrm{Li}_{2} \mathrm{Pd}(\mathrm{C} \equiv \mathrm{CR})_{4}$, which is not an active catalyst for promoting cross-coupling reactions. ${ }^{12,13}$ As shown in Table 1, cross-coupling reaction of octyl bromide with $\mathrm{PhC} \equiv \mathrm{CMgX}$ appeared to be sluggish (entry 4). To avoid the side reaction and increase the yield of $\mathbf{4}$, it was envisaged that a slow addition of the Grignard reagent to the reaction mixture would slow the dimerization process. Indeed, the yield of the cross-coupling reaction increased to $83 \%$ (entry 5 ). $\mathrm{Ph}_{3} \mathrm{P}$ was essential for avoiding the oxidative dimerization of alkyne (entry 5), a much lower yield being observed when ${ }^{t} \mathrm{Bu}_{2} \mathrm{MeP}$ was used (entries 7-9). Bidentate ligand, dppb, was not effective at all for the transformation shown in eq 1 (entry 10). When $\mathrm{Pd}\left(\mathrm{PPh}_{3}\right)_{4}$ was employed under slow addition conditions, the yield of $\mathbf{4}$ was unsatisfac-

(10) (a) Wang, S.; Thomas, S. A. Org. Lett. 2000, 2, 2857-2860. (b) Negishi, E.-i.; Hata, M.; Xu, C. D. Org. Lett. 2000, 2, 3687-3689. (c) Abele, E.; Rubina, K.; Fleisher, M.; Popelis, J.; Arsenyan, P.; Lukevics, E. Appl. Organomet. Chem. 2002, 16, 141-147. (d) Damle, S. V.; Seomoon, D.; Lee, P. H. J. Org. Chem. 2003, 68, 7085-7087.

(11) Yang, C. L.; Nolan, S. P. J. Org. Chem. 2002, 67, 591-593.

(12) Negishi, E.-i.; Anastasia, L. Chem. Rev. 2003, 103, 1979-2017.

(13) Negishi, E.-i.; Akiyoshi, K.; Takahashi, T. J. Chem. Soc., Chem. Commun. 1987, 477-478.
Table 1. Palladium-Catalyzed Cross Coupling of Phenylmagnesium Iodide with Octyl Bromide under Various Conditions

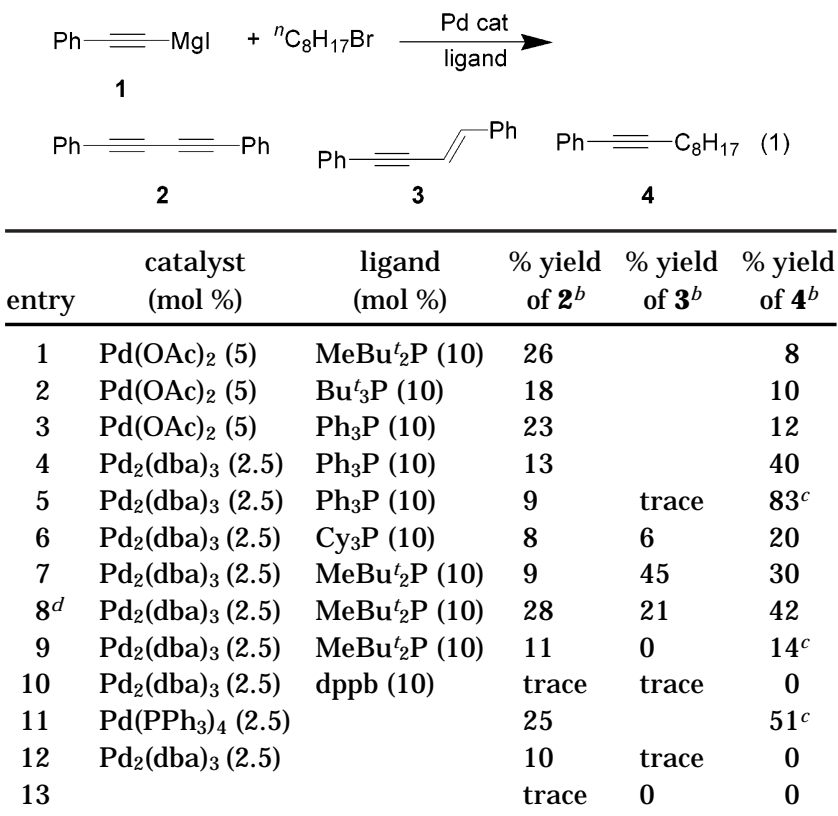

${ }^{a}$ Typical reaction conditions: A mixture of octyl bromide, phenylethynylmagnesium iodide, palladium catalyst, and ligand in THF was refluxed for $8 \mathrm{~h}$, unless otherwise mentioned. ${ }^{b}$ Isolated yields. ${ }^{c}$ Phenylethynylmagnesium iodide was added dropwise to the reaction mixture containing octyl bromide, palladium catalyst, and ligand at refluxing temperature. ${ }^{d}$ Reaction temperature: $45-50{ }^{\circ} \mathrm{C}$.

tory (entry 11$)$. It is noteworthy that both $\mathrm{Pd}_{2}(\mathrm{dba})_{3}$ and $\mathrm{Ph}_{3} \mathrm{P}$ are essential for this catalytic process (entries 12 and 13).

Table 2 summarizes the representative examples of the cross-coupling reactions of phenyl- or silyl-substituted alkynyl Grignard reagents with a range of alkyl halides (eq 2). Either bromide or iodide gave satisfactory yields of the coupling products. It is interesting to note that one of the two carbon-bromine bonds in dibromide can be selectively replaced when 1 equiv of the Grignard reagent was employed (entry 17). Bis-alkynylation was obtained in the presence of 3 equiv of the Grignard reagent under similar conditions (eq 3).

Unexpectedly, alkyl-substituted alkynyl Grignard reagents did not undergo coupling reactions with alkyl halides under

Table 2. $\mathrm{Pd}_{2}(\mathrm{dba})_{3}-\mathrm{Ph}_{3} \mathrm{P}$-catalyzed Cross-Coupling Reaction of Alkyl Halide and Pheny- or Trimethylsilyl-Substituted Alkynyl Grignard Reagen

$$
\mathrm{R}=\mathrm{MgX}+\mathrm{R}^{\prime}-\mathrm{Y} \frac{\mathrm{Pd}_{2}(\mathrm{dba})_{3}}{\mathrm{PPh}_{3}} \mathrm{R} \rightleftharpoons \mathrm{R}^{\prime}
$$

\begin{tabular}{cllllc}
\hline entry & $\mathrm{R}$ & $\mathrm{X}$ & \multicolumn{1}{c}{$\mathrm{R}^{\prime}$} & $\mathrm{Y}$ & \% yield \\
\hline 14 & $\mathrm{Ph}$ & $\mathrm{I}$ & ${ }^{\mathrm{n}} \mathrm{C}_{8} \mathrm{H}_{17^{-}}$ & $\mathrm{Br}$ & 83 \\
15 & $\mathrm{Ph}$ & $\mathrm{I}$ & ${ }^{\mathrm{n}} \mathrm{C}_{4} \mathrm{H}_{9^{-}}$ & $\mathrm{I}$ & 86 \\
16 & $\mathrm{TMS}$ & $\mathrm{I}$ & ${ }^{\mathrm{n}} \mathrm{C}_{8} \mathrm{H}_{17^{-}}$ & $\mathrm{Br}$ & 65 \\
17 & $\mathrm{TMS}$ & $\mathrm{Br}$ & $\mathrm{Br}^{\mathrm{B}}\left(\mathrm{CH}_{2}\right)_{6^{-}}$ & $\mathrm{Br}$ & 77 \\
\hline
\end{tabular}




$$
\begin{gathered}
\mathrm{TMS}=\mathrm{Mgl}+\mathrm{Br}\left(\mathrm{CH}_{2}\right)_{\mathrm{n}} \mathrm{Br} \underset{\mathrm{Pd}_{2}(\mathrm{dba})_{3} 2.5 \mathrm{~mol} \%}{\stackrel{\mathrm{PPh}_{3} 10 \mathrm{~mol} \%}{\longrightarrow}} \\
\mathrm{TMS} \stackrel{-}{-}\left(\mathrm{CH}_{2}\right)_{\mathrm{n}}=\mathrm{TMS} \\
\mathrm{n}=981 \% \\
\mathrm{n}=763 \%
\end{gathered}
$$

these conditions. Alkynyllithiums have been shown to be at least as reactive as the corresponding alkynylzincs. Crosscoupling reactions using these nucleophiles, however, were generally unsatisfactory, in particular when $\mathrm{Cl}_{2} \mathrm{Pd}\left(\mathrm{PPh}_{3}\right)_{2}$ was used as the catalyst. ${ }^{12,13}$ It is well documented that alkynyllithiums react with primary halides in the presence of diamines or HMPA to give the corresponding coupling products. ${ }^{15}$ In the absence of such an additive, reaction of phenylethynyllithium with octyl bromide in refluxing THF, for example, afforded 4 in less than $30 \%$ yield. As shown in Table 1 , the nature of the palladium catalyst appeared to be important in dictating the selectivity of the reaction. Since $\mathrm{Pd}_{2}(\mathrm{dba})_{3}$ is an active catalyst for alkynylation of alkyl bromides and iodides, we examined a similar reaction using alkynyllithiums and found that the cross-coupling products were obtained in satisfactory yields (eq 4). Apparently, $\mathrm{Pd}_{2-}$ $(\mathrm{dba})_{3}$ plays an important role in promoting such coupling reactions. The results are summarized in Table 3. Different substituents ranging from phenyl and TMS to simple alkyl groups at the alkynyllithiums can be used. Selective monoalkynylation of dibromoalkanes was achieved in good yields.

In conclusion, we have demonstrated useful $\mathrm{Pd}_{2}(\mathrm{dba})_{3}-$ $\mathrm{Ph}_{3} \mathrm{P}$-catalyzed Kumada-Corriu coupling conditions for unactivated alkyl bromides or iodides with an alkynyl nucleophile. Under these conditions, alkynyllithiums were active alkynylation reagents in facilitating $\mathrm{C}_{\mathrm{sp}}-\mathrm{C}_{\mathrm{sp}} 3$ bond formation. The better performance of $\mathrm{Ph}_{3} \mathrm{P}$ ligand than that of trialkylphosphine ligands indicates that this cross-coupling

(14) Ishiyama, T.; Abe, S.; Miyamura, N.; Suzuki, A. Chem. Lett. 1992, 691-694.

(15) (a) Brandsma, L. Preparative Acetylenic Chemistry, 2nd ed.; Elsevier: Amsterdam, 1988. (b) Sankaranarayanan, S.; Chattopadhyay, S. Tetrahedron: Asymmetry 1998, 9, 2627-2633. (c) Tyman, J.; Ghorbanian, S.; Muir, M.; Tychopoulous, V.; Bruce, I.; Fisher, I. Synth. Commun. 1989, $19,179-188$.
Table 3. $\mathrm{Pd}_{2}(\mathrm{dba})_{3}-\mathrm{Ph}_{3} \mathrm{P}$-Catalyzed Cross-Coupling Reaction of Alkyl Bromide and Substituted Alkynyllithium

$$
\mathrm{R}=\mathrm{Li}+\mathrm{R}^{\prime}-\mathrm{Br} \underset{\mathrm{Pd}_{2}(\mathrm{dba})_{3}}{\mathrm{PPh}_{3}} \mathrm{R}=\mathrm{R}^{\prime}
$$

\begin{tabular}{|c|c|c|c|}
\hline entry & $\mathrm{R}$ & $\mathrm{R}^{\prime}$ & $\%$ yield \\
\hline 18 & $\mathrm{Ph}$ & ${ }^{\mathrm{n}} \mathrm{C}_{4} \mathrm{H}_{9^{-}}$ & 88 \\
\hline 19 & $\mathrm{Ph}$ & ${ }^{\mathrm{n}} \mathrm{C}_{8} \mathrm{H}_{17^{-}}$ & 91 \\
\hline 20 & TMS & ${ }^{\mathrm{n}} \mathrm{C}_{8} \mathrm{H}_{17^{-}}$ & 84 \\
\hline 21 & $\mathrm{Ph}$ & $\mathrm{Br}\left(\mathrm{CH}_{2}\right)_{4^{-}}$ & 86 \\
\hline 22 & $\mathrm{Ph}$ & $\mathrm{Br}\left(\mathrm{CH}_{2}\right)_{7^{-}}$ & 80 \\
\hline 23 & $\mathrm{Ph}$ & $\mathrm{Br}\left(\mathrm{CH}_{2}\right)_{8^{-}}$ & 81 \\
\hline 24 & $\mathrm{Ph}$ & $\mathrm{Br}\left(\mathrm{CH}_{2}\right)_{9^{-}}$ & 79 \\
\hline 25 & $\mathrm{Ph}$ & $\mathrm{Br}\left(\mathrm{CH}_{2}\right)_{10^{-}}$ & 73 \\
\hline 26 & $\mathrm{Ph}$ & $\mathrm{Br}\left(\mathrm{CH}_{2}\right)_{12^{-}}$ & 69 \\
\hline 27 & TMS & $\mathrm{Br}\left(\mathrm{CH}_{2}\right)_{3^{-}}$ & 84 \\
\hline 28 & TMS & $\mathrm{Br}\left(\mathrm{CH}_{2}\right)_{6^{-}}$ & 82 \\
\hline 29 & nHex & $\mathrm{PhC} \equiv \mathrm{C}\left(\mathrm{CH}_{2}\right)_{4^{-}}$ & 83 \\
\hline 30 & nBu & $\mathrm{PhC} \equiv \mathrm{C}\left(\mathrm{CH}_{2}\right)_{10^{-}}$ & 67 \\
\hline 31 & ${ }^{\mathrm{n} H e x}$ & $\mathrm{BnO}\left(\mathrm{CH}_{2}\right)_{8^{-}}$ & 72 \\
\hline 32 & ${ }^{\mathrm{n}} \mathrm{Hex}$ & $\left(2,6-\mathrm{Me}_{2} \mathrm{C}_{6} \mathrm{H}_{3}\right) \mathrm{O}\left(\mathrm{CH}_{2}\right)_{4}^{-}$ & 76 \\
\hline 33 & nBu & $\left(3,5-\mathrm{Me}_{2} \mathrm{C}_{6} \mathrm{H}_{3}\right) \mathrm{O}\left(\mathrm{CH}_{2}\right)_{8^{-}}$ & 69 \\
\hline
\end{tabular}

reaction may be a reductive elimination-controlled process. This study may provide an impetus for further investigations on the nature of ligands toward the development of new catalytic systems.

Acknowledgment. We thank the National Science Council and the Ministry of Education of the Republic of China for financial support.

Supporting Information Available: Experimental details of the $\mathrm{Pd}_{2}(\mathrm{dba})_{3} / \mathrm{PPh}_{3}$-catalyzed reactions of alkyl halides with alkynyl nucleophiles and ${ }^{1} \mathrm{H}$ NMR spectra of new compounds. This material is available free of charge via the Internet at http://pubs.acs.org.

OL049686G 